\title{
Ensino de robótica para alunos com altas habilidades
}

\author{
Maria Caroline Cordeiro, Eloí Lucas Amendola \\ Gomes \\ Estudantes de Engenharia Eletrônica \\ Universidade Tecnológica Federal do Paraná \\ Toledo, Paraná, Brasil \\ e-mail: marial_cacal@hotmail.com, \\ eloilucasag@gmail.com
}

\author{
Fábio Rizental Coutinho \\ Coordenador de Engenharia Eletrônica \\ Universidade Tecnológica Federal do Paraná \\ Toledo, Paraná, Brasil \\ e-mail: fabiorizentalcoutinho@gmail.com
}

\begin{abstract}
Resumo - Considerando a importância e a necessidade de sistemas educacionais inclusivos, o objetivo deste projeto é ofertar aulas de robótica para crianças e adolescentes com altas habilidades. Estimulando e aperfeiçoando o conhecimento dos alunos através do Arduino, o qual foi utilizado para realização de vários experimentos voltados a eletrônica. São ministradas aulas teóricas e práticas, as quais resultaram em um bom desempenho dos alunos, destacandose a facilidade de compreensão, melhor realização de atividades em grupo e raciocínio lógico deles. Este projeto permite que a universidade trabalhasse junto à comunidade se apresentando como propagadora de saberes e conhecimentos, bem como a evolução dos alunos com o estímulo a aprendizagem.
\end{abstract}

Palavras-chave: altas habilidades, robótica, inclusão.

\section{INTRODUÇÃO}

Diferentemente da maioria dos países do mundo, a superdotação no Brasil é predominantemente ignorada, quando se trata da prática educacional. Como nos casos das deficiências, a superdotação deve ser avaliada, oferecendo-se ao indivíduo condições educacionais adequadas ao seu potencial. Num país pleno de carências, não se considera relevante $\mathrm{o}$ atendimento diferenciado a quem já foi privilegiado com um dom especial. Os superdotados estão escondidos nas salas de aula comuns, como se seus talentos fossem invisíveis [1]

Todo talento deve ser estimulado, sob pena de ser subaproveitado. Entretanto, existe uma hipótese antiquada, segundo a qual a criança superdotada encontra um caminho para desenvolver seus potenciais sob quaisquer circunstâncias [2].

Como mostrado no artigo da revista Unisinos (2016), o qual ressalta a tendência de alunos com AH/SD (Altas habilidades/Superdotação) a desafiar regras/autoridade, contudo, é algo que precisa ser trabalhado com vistas a favorecer a convivência em grupo. [3].

Segundo o projeto de "Desenvolvimento de competências através de campeonato de robótica para estudantes com altas habilidades/superdotação", acreditase que o fomento efetivo de atividades relacionadas as ciências exatas e engenharia nos diversos níveis de ensino, possibilitará em descobertas de novos talentos, ou ainda permitirá aperfeiçoar e motivar mais o desenvolvimento de vocações para essas áreas, com repercussão positiva na sociedade brasileira.[4].

A criança superdotada tem uma curiosidade acentuada pelo seu desejo de saber mais sobre o seu tema de interesse. Isso faz com que essa criança seja uma grande questionadora e esteja sempre em busca de respostas para as suas questões. "A época dos 'porquês', típica dos 3 e 4 anos, aparece no superdotado muito antes e poderíamos dizer que não tem fim". . [5].

Considerando a importância e a necessidade de sistemas educacionais inclusivos, o objetivo deste projeto é ofertar aulas de robótica para crianças e adolescentes com altas habilidades com o intuito de incentivar, estimular e aperfeiçoar seus conhecimentos nessa área, despertando também um interesse na área de eletrônica e, por consequência, expandir seus conhecimentos, como também divulgar atividades de engenharia, especialmente o curso de Engenharia Eletrônica e a Universidade Tecnológica Federal do Paraná ao público da região.

A criação deste projeto deu-se também pela necessidade de escolas públicas de Toledo-PR para a realização de atividades diferentes de acordo com a aptidão dos alunos.

\section{METODOLOGIA}

Para o ensino de robótica optou-se nessa primeira etapa do curso por oferecer aulas focadas em um projeto integrador do conhecimento, o tema escolhido foi o de desenvolvimento de um carrinho robô que pudesse realizar um trajeto desviando de obstáculos e realizando comandos como parar, rodar, voltar ou avançar.

Optou-se pela utilização do ARDUINO UNO, mostrado na Figura 1, como plataforma para o controle do carrinho, devido à flexibilidade de conteúdos que podem ser abordados, visando proporcionar um equipamento mais prático, acessível e de software livre. Também foram feitos desafios com o intuído de fixação e percepção do nível de compreensão.

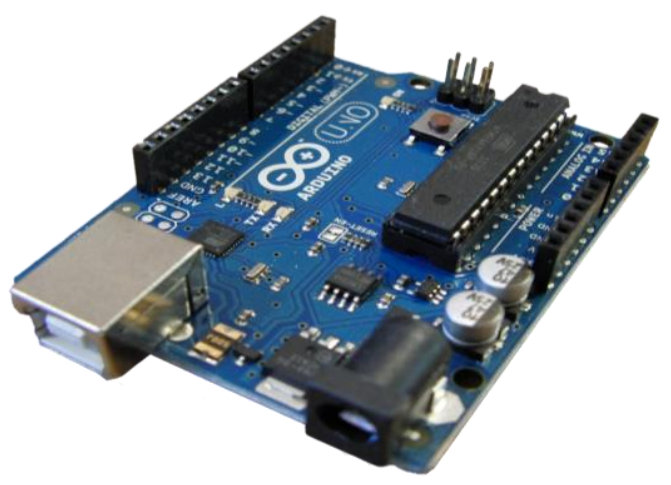

Figura 1. Arduino UNO [6]. 
Para a participação no projeto, foram selecionados alunos com altas habilidades por meio de avaliação psicopedagógica, este processo de seleção foi realizado pelas escolas através de questionários e atividades especificas, levando até três meses para finalização desse diagnóstico. Nos encontros do projeto os alunos foram acompanhados pela pedagoga.

Foram mescladas aulas teóricas e práticas, dividindo-as em duas horas por encontro, as quais viabilizaram mais atenção aos conteúdos propostos e uma melhoria na compreensão. Até o momento estão totalizadas $24 \mathrm{~h}$ de projeto com 6 alunos participantes de escola pública entre a faixa etária de nove a quatorze anos. O quadro 1 demonstra como foram divididas as aulas.

QUADRO I.

\begin{tabular}{|c|c|}
\hline Aula & Conteúdos \\
\hline 1 & $\begin{array}{l}\text { Matriz de contato, jumpers, led's (light emission } \\
\text { diode) e resistores. }\end{array}$ \\
\hline 2 & $\begin{array}{l}\text { Revisão do conteúdo anterior, apresentação do } \\
\text { Arduino, explicação de ligação do Arduino ao } \\
\text { computador e código para ligar um led. }\end{array}$ \\
\hline 3 & $\begin{array}{l}\text { Revisão do conteúdo anterior, explicação motor } \\
\text { DC, servo motor e motor de passo (no conteúdo de } \\
\text { motores tem-se necessidade de revisar } \\
\text { matemática). }\end{array}$ \\
\hline 4 & $\begin{array}{l}\text { Revisão do conteúdo anterior, início do código } \\
\text { motor DC com o funcionamento para uma roda (no } \\
\text { conteúdo de rotação tem-se necessidade de revisar } \\
\text { física). }\end{array}$ \\
\hline 5 & $\begin{array}{l}\text { Revisão do conteúdo anterior, teste do código de } \\
\text { um motor e início da explicação do código de dois } \\
\text { motores com o funcionamento para duas rodas. }\end{array}$ \\
\hline 6 & $\begin{array}{l}\text { Revisão do conteúdo anterior e teste do código } \\
\text { para dois motores. }\end{array}$ \\
\hline 7 & $\begin{array}{l}\text { Revisão do conteúdo anterior e início da } \\
\text { explicação do sensor ultrassônico (no conteúdo de } \\
\text { sensor ultrassônico tem-se necessidade de revisar } \\
\text { física). }\end{array}$ \\
\hline 8 & $\begin{array}{l}\text { Revisão do conteúdo anterior e início da } \\
\text { explicação do código de sensor ultrassônico. }\end{array}$ \\
\hline 9 & $\begin{array}{l}\text { Revisão do conteúdo anterior e explicação da } \\
\text { ponte H. }\end{array}$ \\
\hline 10 & $\begin{array}{l}\text { Revisão do conteúdo anterior e desafio para os } \\
\text { alunos realizarem a junção do código com dois } \\
\text { motores e sensor ultrassônico. }\end{array}$ \\
\hline 11 & $\begin{array}{l}\text { Revisão do conteúdo anterior e teste do código } \\
\text { com dois motores e sensor ultrassônico. }\end{array}$ \\
\hline 12 & $\begin{array}{l}\text { Revisão do conteúdo anterior e montagem final do } \\
\text { carrinho com o funcionamento de dois motores e } \\
\text { sensor ultrassônico. }\end{array}$ \\
\hline
\end{tabular}

De início foram feitas revisões relacionadas à matemática, física e eletrônica, com o intuito de identificar o nível de conhecimento dos mesmos e consecutivamente executar tarefas mais especificas as necessidades.

Após passou-se a inserir conteúdos relacionados ao ARDUINO e linguagem de programação, possibilitando assim trabalhar com o raciocínio lógico dos alunos. A próxima etapa foi iniciar passo a passo a montagem de um carrinho, no qual é abordado o assunto de matriz de contato, jumpers, LED'S, motores, sensores, entre outros componentes eletrônicos ligados a montagem do carrinho e caso os alunos demostrem um domínio consideravelmente bom do conteúdo será visto outras aplicações na eletrônica.

Destaca-se a suma importância da explicação teórica e da execução de programas passo a passo para cada etapa, para que ao final seja possível a montagem de um robô móvel com sensor ultrassônico que consiga andar desviando de obstáculos.

Na Figura 2 é apresentado um dos protótipos de carrinho com sensor ultrassônico montado pelos alunos e na Figura 3 os alunos em aulas práticas e teóricas.

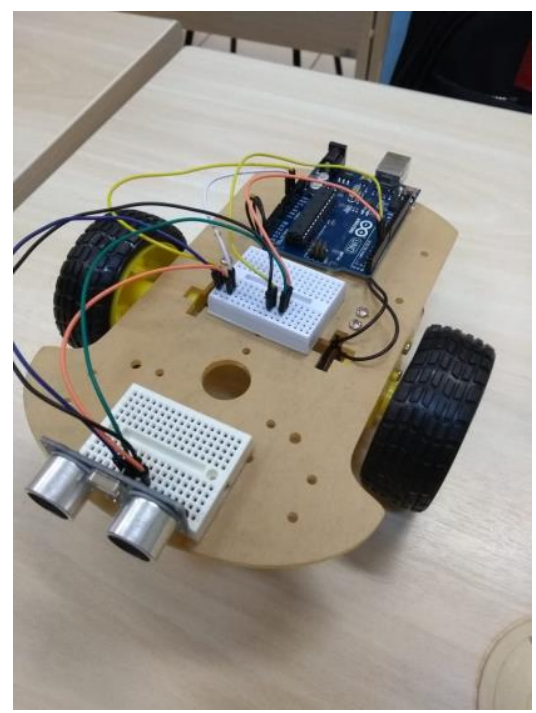

Figura 2. Protótipo de carrinho com sensor ultrassônico montado pelos alunos.

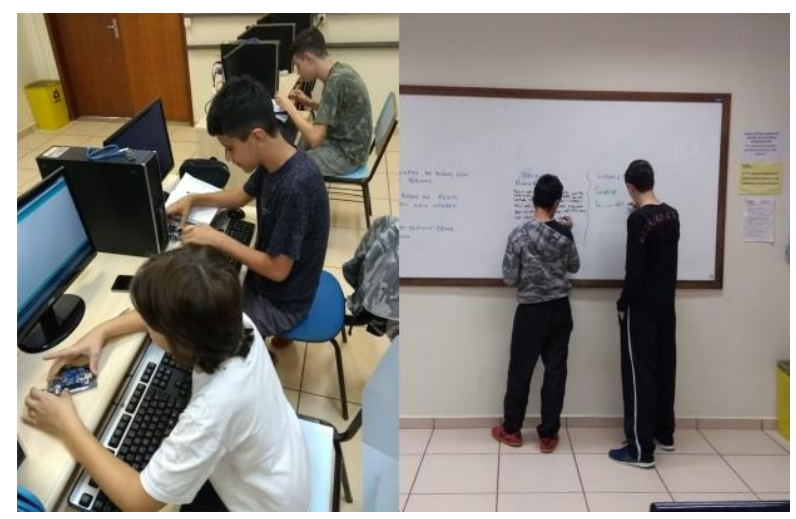

Figura 3. Alunos em aulas práticas e teóricas.

Nas aulas sempre é realizada uma breve revisão dos conteúdos previamente vistos antes de adicionar novos. Também é abordada a ideia de um aluno explicar o que entendeu aos outros, pois nem sempre a linguagem acadêmica consegue ser suficientemente simples para o público em questão. Por isso, instiga-se os alunos a se expressarem para os colegas com suas palavras ao mesmo tempo que se estimula o trabalho em grupo.

Ao decorrer do projeto, foi analisado as dificuldades iniciais dos alunos, evidencia-se que eles tiveram uma grande facilidade de absorção do conteúdo, evolução do raciocínio lógico e matemático, e se teve dificuldade inicial com dispersões devido a cada aluno demonstrar seu raciocínio diferente. 
A separação em aulas teóricas e práticas ajudam no andamento da turma, bem como a compreensão dos alunos, possibilitando trabalhar uma gama alta de atividades devido ao grande suporte encontrado pelo Arduino. Na Figura 4 é apresentado um protótipo montado pelos alunos.

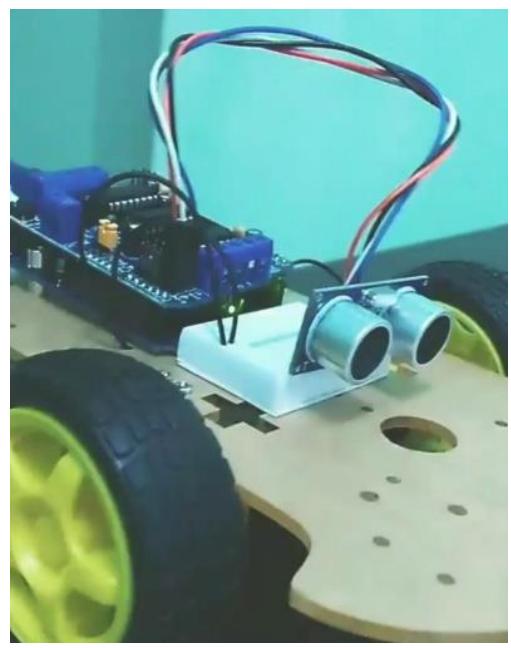

Figura 4. Protótipo montado pelos alunos.

Durante o projeto, foram realizados desafios a fim de verificar se os alunos haviam tido uma boa compreensão dos conteúdos, as notas dos desafios foram avaliadas de 0 a 10. O Gráfico 1 apresenta os resultados por conteúdo.

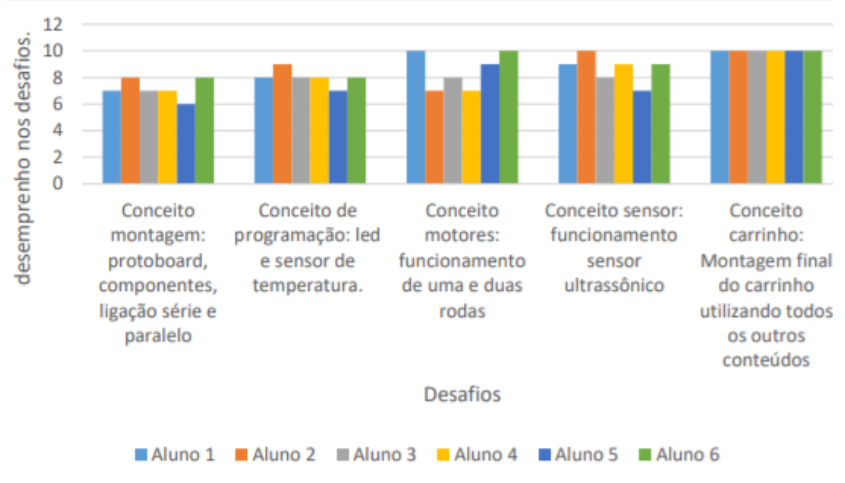

Gráfico 1: Análise do desempenho dos alunos sobre os conteúdos abordados nos desafios.

Mesmo alguns alunos não conseguindo completar totalmente algumas atividades, houve uma tendência de aumento de notas da turma (Gráfico 1), ou seja, com o passar do tempo eles melhoraram o desempenho, e assim todos foram capazes de realizar a montagem e execução do carrinho.

\section{CONSIDERAÇÕES FINAIS}

Os resultados obtidos até o momento foram positivos, mostrando que mesmo se tratando de alunos de faixa etária entre nove e quatorze anos, e por apresentarem inicialmente certa resistência em sair de sua individualidade, eles demonstraram total capacidade de aprendizagem e compreensão dos conteúdos, conseguindo assim executar as atividades práticas em tempo hábil.

Este projeto permite que a universidade trabalhe junto à comunidade se apresentando como propagadora de saberes e conhecimento. Por meio destas atividades a universidade é beneficiada, sendo divulgada e atraindo interessados na graduação, juntamente aos alunos participantes que entram em contato com a vida acadêmica e com isso adquirem experiência e conhecimento na área de Engenharia Eletrônica.

A dedicação dos alunos só reforça o quanto é importante sistemas educacionais inclusivos, pois ao comparar os alunos no início do projeto com o atual momento (6 meses de projeto) é nítida a diferença comportamental, tanto individual quanto coletiva. Alunos que antes não interagiam com os colegas passaram a pedir a realização das tarefas em grupo, e os que resistiam para prestar atenção, estão focando e auxiliando nas explicações.

\section{REFERÊNCIAS}

[1] C. M. B. Cupertino, "Educação dos diferentes no Brasil: o caso da superdotação", Anais do 1o Congresso Internacional de Educação da Alta Inteligência, promovido pela Universidade da Provincia de Cuyo e pelo Instituto San Bernardo de Claraval, Mendoza, Argentina, Agosto de 1998.

[2] E. Landau, "A coragem de ser superdotado". São Paulo: Arte e Ciência, 2002.

[3] B. A. Martins, M. C. M. Chacon, "Crianças precoces com indicadores de altas habilidades/superdotação: as características que contrariam a imagem de aluno 'ideal", Revista Unisinos. $2016 . \quad$ Disponível em: <http://revistas.unisinos.br/index.php/educacao/article/viewFile/ed u.2016.201.10/5236>. Acesso em: 07 jun. 2019.

[4] E. F. F. Ramírez, et al. "Desenvolvimento de competências através de campeonato de robótica parar estudantes com altas habilidades/superdotação”.COBENGE. Juiz de Fora. 2014

[5] A. Izquierdo. "A criança superdotada: Conceito, /diagnóstico e Educação - In: Necessidades Educacionais Específicas”. São Paulo: Artmed, 2007.

[6] Flickr, Arduino UNO, Disponível em https://www.flickr.com/photos/creative_tools/5407788592/in/photo strem/, Acesso em: 10 jul. 2019. 